\title{
Chapter 4 \\ Developing Ecosystem Service Models for Urban Planning: A Focus on Micro-Climate Regulation
}

Text and graphics of this chapter are based on: Zardo L, Geneletti D, Pérez-Soba M, Van Eupen M (2017) Estimating the cooling capacity of green infrastructures to support urban planning. Ecosyst Serv 26:225-235. https://doi.org/10.1016/j. ecoser.2017.06.016.

\subsection{Introduction}

Among the natural disasters occurring in Europe, heat waves cause the most human fatalities (EEA 2012). During the summer of 2003, for example, the heat wave in Central and Western Europe is estimated to have caused up to 70,000 excess deaths over a four-month period (EEA 2012). During the same period, in Germany alone, heat-related hospitalization costs had increased six-fold, not including the cost of ambulance treatment, while heat-related reduction of work performance caused an estimated output loss of almost $0.5 \%$ of the GDP (Hübler et al. 2008). In many regions of the world, climate change is expected to increase the effects of heat waves, including the rising of temperatures in cities (Koomen and Diogo 2015).

As shown in the previous chapter, the creation and enhancement of Urban Green Infrastructures (UGI) to regulate micro-climate and combat summer heat is one of the most common Ecosystem-based adaptation measure. By the virtue of their cooling capacity, i.e. capacity to modify temperature, humidity and wind fields, UGI can contribute to reducing high temperatures in cities, and lowering the related health risks (Lafortezza et al. 2013; Escobedo et al. 2015). Studies have shown that UGI have the capacity to mitigate high temperature in the summer, lowering them up to $6{ }^{\circ} \mathrm{C}$ (Souch and Souch 1993; McPherson et al. 1997). The creation and restoration of UGI, maximizing their cooling capacity, can reduce energy costs for air conditioning in summer and contribute to lowering mortality induced by higher temperatures (Koomen and Diogo 2015).

Urban plans represent a key governance instrument to design and enhance UGI (Kremer et al. 2013). However, as shown by our review in Chap. 3, despite the good 
awareness of the potential role of UGI to address climate change challenges, their inclusion in plans at the urban level often lacks sufficient baseline information (Geneletti and Zardo 2016). UGI may be very different in nature, including typologies such as parks, gardens, forests, green roofs and walls, and rivers (Naumann et al. 2011; Pauleit et al. 2011; EEA 2012). In turn, each typology may differ in key components (e.g. soil cover, tree canopy cover, size and shape), thus providing different ES, with different capacity (Bolund and Hunhammar 1999; Chang et al. 2007; de Groot et al. 2010; Bowler et al. 2010b).

This chapter presents an approach for estimating the cooling capacity provided by UGI tailored to support urban planning. The proposed approach, by providing guidance for UGI planning and design, is expected to support urban planners in effectively including the design and enhancement of UGI into the planning practice as a measure to cool cities and combat urban heat islands. In the remainder of the chapter, the approach is described, and applied to the city of Amsterdam, The Netherlands.

\subsection{Methods to Assess the Cooling Capacity of UGI}

As shown in Fig. 4.1, the proposed approach consists of five main steps. As a first step, the ecosystem functions of UGI that determine the cooling capacity are identified, following the cascade model (Haines-Young and Potschin 2010). Hence, the components associated to such ecosystem functions are defined, and their individual contribution to the cooling capacity assessed. Subsequently, the contributions are aggregate to determine the overall cooling capacity of the UGI. More specifically, the cooling capacity and the associated change in temperature are assessed for a set of UGI typologies, consisting of different combinations of tree canopy coverage, soil cover, and size. The proposed approach is based on an extensive analysis of the literature to determine the cooling capacity of UGI in three different climatic regions: Atlantic region, Continental region and Mediterranean region, as defined according to the classification of climate regions by the European Topic Center on Biological Diversity (ETC/BD 2006).

Shading, evapotranspiration (ETA) and wind shielding are the three ecosystem functions that determine the cooling capacity of UGI (EEA 2012; Gómez-Baggethun and Barton 2013; McPhearson et al. 2013; Smith et al. 2013; Larondelle and Haase 2013). In fact, vegetation regulates urban micro-climate in three ways: (i) by intercepting incoming solar radiation (shading), (ii) through the process of evapotranspiration, and (iii) by altering air movement and heat exchange. Shading and evapotranspiration are the ones that contribute the most to the cooling effect of UGI (Skelhorn et al. 2014). The contribution of wind to cooling capacity assessments, on the other hand, is rather complex to consider given its dependency on case-specific conditions (e.g. presence of buildings and directions of streets), that are not directly linked to ecosystem functions or components of UGI (Bowler et al. 2010b). Shading and evapotranspiration are determined by the structure of the ecosystem, i.e., the 


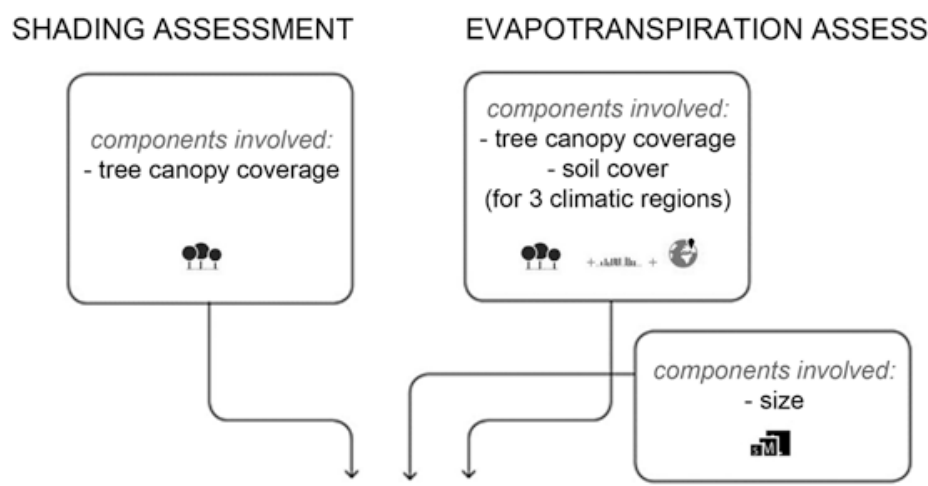

COOLING CAPACITY ASSESSMENT

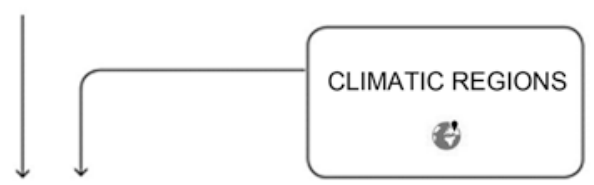

\section{COOLING CAPACITY OF UGI TYPOLOGIES AND EXPECTED TEMPERATURE CHANGE}

Fig. 4.1 Flowchart of the proposed approach to assess the cooling capacity of UGI

architecture of its components. In particular, as shown in Fig. 4.1, shading and evapotranspiration are associated to three specific components of UGI; namely, tree canopy coverage, soil cover, and size (Taha et al. 1991; Akbari et al. 1992; Souch and Souch 1993; Chang et al. 2007; Cao et al. 2010; Bowler et al. 2010b; Schwarz et al. 2011; Larondelle and Haase 2013).

\subsubsection{Shading and Evapotranspiration Assessment}

Several studies show evidence of cooler air temperature beneath individual or clusters of trees, highlighting the amount of shading as an important factor affecting temperatures (Taha et al. 1991; Akbari et al. 1992; Bowler et al. 2010b; Schwarz et al. 2011; Larondelle and Haase 2013). Among the indicators proposed in the literature, the tree canopy coverage, expressed as the percentage of the ground area shaded by tree canopies relative to the total open area, is here adopted (Potchter et al. 2006; Strohbach and Haase 2012). Accordingly, assuming a linear relationship between the presence of tree covers and shading (Potchter et al. 2006), the assessment of the contribution of shading can be based on a visual estimation. For example, a shading score equal to " $\mathrm{x}$ " is assigned to an UGI with an $\mathrm{x} \%$ tree canopy coverage. Noteworthy, the contribution given by trees with canopy lower than two 
meters is here overlooked, as they do not provide shade that is useful for human beneficiaries. Nevertheless, such vegetation has a significant contribution in terms of evapotranspiration.

Tree canopy coverage, soil cover and tree species are the three main components that jointly affect evapotranspiration (Taha et al. 1991; Akbari et al. 1992; Souch and Souch 1993; Allen et al. 1998; Bowler et al. 2010b; Schwarz et al. 2011; Larondelle and Haase 2013). In this context, the focus is however on the first two components mainly because information of tree species is hardly available at city scale, whereas, at this scale, differences in evapotranspiration across different combinations of species can be considered negligible (Souch and Souch 1993). On the other hand, the climatic region is included as a crucial factor to consider given that it greatly affects the evapotranspiration: in warm and dry areas, evapotranspiration is more effective than in humid or cool climates (Taha et al. 1991; Akbari et al. 1992; McPherson et al. 1997; Bowler et al. 2010b).

Following the approach by Allen et al. (1998), the evapotranspiration is calculated as:

$$
E T_{c}=K_{c} \cdot E T_{0}
$$

where $\mathrm{ET}_{\mathrm{c}}$ is the tree or soil cover evapotranspiration (ETA) under conditions of unlimited presence of water in the ground (irrigated), $\mathrm{K}_{\mathrm{c}}$ is the tree or soil cover coefficient, and $\mathrm{ET}_{0}$ is the reference evapotranspiration, which takes into account the climatic region of the study area.

Operationally, to estimate the evapotranspiration potential of an UGI, its soil cover and tree canopy coverage are analysed separately to determine the related Kc coefficient. Hence, the evapotranspiration is estimated by multiplying the Kc coefficient by the climate-specific value $\mathrm{ET}_{0}$, again analysing separately the contribution of trees and of the soil cover (e.g., Kremer et al. 2013; Larondelle and Haase 2013; Schwarz et al. 2011). In the proposed approach, the overall evapotranspiration value of the UGI, obtained by adding the different contribution that are expressed in $\mathrm{mm}$ $\mathrm{d}^{-1}$, is then standardized into an evapotranspiration score in the $0-100$ range.

\subsubsection{Cooling Capacity Assessment}

The extent to which shading and evapotranspiration contribute to the overall cooling capacity of the UGI is determined by the size of the UGI itself (Chang et al. 2007; Cao et al. 2010; Bowler et al. 2010b). In fact, shading and evapotranspiration jointly reduce the air temperature, but the impact of evapotranspiration becomes predominant as the area gets larger (Akbari et al. 1992). Specifically, green areas larger than 2-3 ha are cooler than their surroundings, whereas green areas smaller than 2 ha have a limited effect (Chang et al. 2007). Thus, several studies identify the threshold between small parks and large parks around a value of 2 ha (e.g., Bowler et al. 2010b; Cao et al. 2010; Chang et al. 2007; Shashua-Bar and Hoffman 2000). 
Regarding the effects of shading and evapotranspiration on surroundings of trees (based on measurements taken at $12 \mathrm{~m}$ and $5 \mathrm{~m}$ from trees), Akbari et al. (1992) concluded that, for large areas, the cooling capacity depends mainly on evapotranspiration, reaching a distance as far as five times the height of the tree. They also found that shading contributes up to $95 \%$ when directly under the canopy, but its contribution in terms of reducing the temperature (and consequently the energy consumption for air conditioning) is around $40 \%$ for areas larger than 2 ha. According to Chang et al. (2007), size contributes to $60 \%$ of the cooling capacity, and indirectly affects the contribution of ETA. Finally, Shashua-Bar and Hoffman (2000), based on empirical studies, note that in areas smaller than two hectares, the contribution of shading is around $80 \%$ of the total cooling capacity, with the remaining $20 \%$ determined by evapotranspiration.

Therefore, in the proposed approach, the overall cooling capacity of UGI is assessed through a weighted summation of the evapotranspiration and shading scores, using different weights according to size, followed by a standardization of the results into a scale between 0 and 100. More specifically, in areas smaller than two hectares, shading is assigned a weight of 0.8 and evapotranspiration of 0.2 , while in areas larger than two hectares, the weights are of 0.4 and 0.6 , for shading and ETA, respectively. Noteworthy is the case of areas with less than $50 \%$ of tree canopy coverage that may turn to be warm islands instead of cool islands during some part of the day in very hot summer (Chang et al. 2007). To consider this remark, the cooling capacity scores calculated for all areas with tree canopy coverage below $50 \%$ is marked with a " $*$ " to highlight that, in some circumstances, they can also work the other way round.

\subsubsection{UGI Typologies and Expected Temperature Change}

To define different typologies of UGI, the three components of tree canopy coverage, soil cover, and size, were combined. To this end, tree canopy coverage is classified into five intervals: $0-20 \%, 21-40 \%, 41-60 \%, 61-80 \%$ and $81-100 \%$. Soil cover is classified into sealed (all impervious surfaces), bare soil, heterogeneous cover (mixed cover of bare-soil and shrubs, typical of vegetable gardens or inner courts or some vacant lots), grass (fine vegetation), and water, based on the HERCULES soil-cover taxonomy (Cadenasso et al. 2007). Finally, size was divided into two classes: below and above two hectares. By combining these classes of the three components, 50 typologies of UGI are obtained to be further analysed considering the three different climatic regions.

Operationally, to assess the cooling capacity of each UGI typology in each climatic region, data on ET0 and Kc was retrieved from a number of databases, including the CGMS database of the Mars Crop Yield Forecasting System and the FAO (more details in Zardo et al. 2017). Through a literature review, the cooling capacity score of each UGI typology was then associated to an expected change in temperature (see Table 4.1). Indeed, the conversion of cooling capacity scores (from 0 to 100) 
Table 4.1 Overview of some key references about cooling capacity of UGI

\begin{tabular}{l|l|l|l}
\hline Climatic area & $\begin{array}{l}\text { Min cooling } \\
\left({ }^{\circ} \mathrm{C}\right)\end{array}$ & $\begin{array}{l}\text { Max cooling } \\
\left({ }^{\circ} \mathrm{C}\right)\end{array}$ & Reference \\
\hline $\begin{array}{l}\text { Atlantic } \\
\text { (Koppen: Cfb) }\end{array}$ & 1.0 & 3.5 & $\begin{array}{l}\text { Watkins (2002); GLA (2006); Schwarz et al. } \\
(2011) ; \text { Larondelle and Haase (2013) }\end{array}$ \\
\hline $\begin{array}{l}\text { Continental } \\
\text { (Koppen: Cfa) }\end{array}$ & 1.0 & 4.8 & Potchter et al. (2006); Chang et al. (2007) \\
\hline $\begin{array}{l}\text { Mediterranean } \\
\text { (Koppen: Csa) }\end{array}$ & 1.7 & 6.0 & $\begin{array}{l}\text { Taha et al. (1991); Souch and Souch (1993); } \\
\text { Shashua-Bar and Hoffman (2000); Potchter } \\
\text { et al. (2006) }\end{array}$ \\
\hline
\end{tabular}

into changes in air temperature is significantly affected by the climatic region: UGI can lower daily maximum near-surface temperature especially in hot and dry conditions (Taha et al. 1991).

\subsection{Assessing the Cooling Capacity of UGI Typologies}

Figure 4.2 summarizes the assessment of the cooling capacity of 50 different typologies of UGI, for the three climatic regions. From the analysis of the table it is possible to note that $26 \%$ of the UGI typologies have the highest scores (from 81 to 100), $17 \%$ of UGI typologies score between 61 and $80,23 \%$ from 41 to $60,23 \%$ from 21 to 40 , and $12 \%$ score from 0 to 20 . Indeed, size is the most influent component among the three; for example, all UGI scoring more than 60 have a size above the two hectares, while only $3 \%$ of the UGI that are above the two hectares score less than 60 below. Furthermore, no UGI with size smaller than two hectares scores more than 60 . While scores between 41 and 60 comprise mainly areas smaller than two hectares (91\%). This includes all the UGI with $100 \%$ of tree canopy coverage, and most of UGI with $80 \%$ of tree canopy coverage. The UGI scoring between 21 and 40 are smaller than two hectares and have tree canopy coverage between 20 and $60 \%$. Thus, the second most influential component, after the size, is the tree canopy coverage, followed by soil cover.

In terms of the expected temperature changes, according to the climatic region, each score implies a different temperature decrease. As shown in Fig. 4.3, the Mediterranean region is where larger changes occur, followed by the Continental area and the Atlantic region. For example, an UGI with a cooling capacity score of 100 , in the Atlantic region, can decrease the temperature up to $3.5^{\circ} \mathrm{C}$, while the same UGI, in the Mediterranean region, can reduce the temperature of up to $6{ }^{\circ} \mathrm{C}$. Therefore, investing on UGI to improve their cooling capacity has different implications in terms of temperature decrease, depending on the climatic region (e.g., see grey rectangle in Fig. 4.3). 


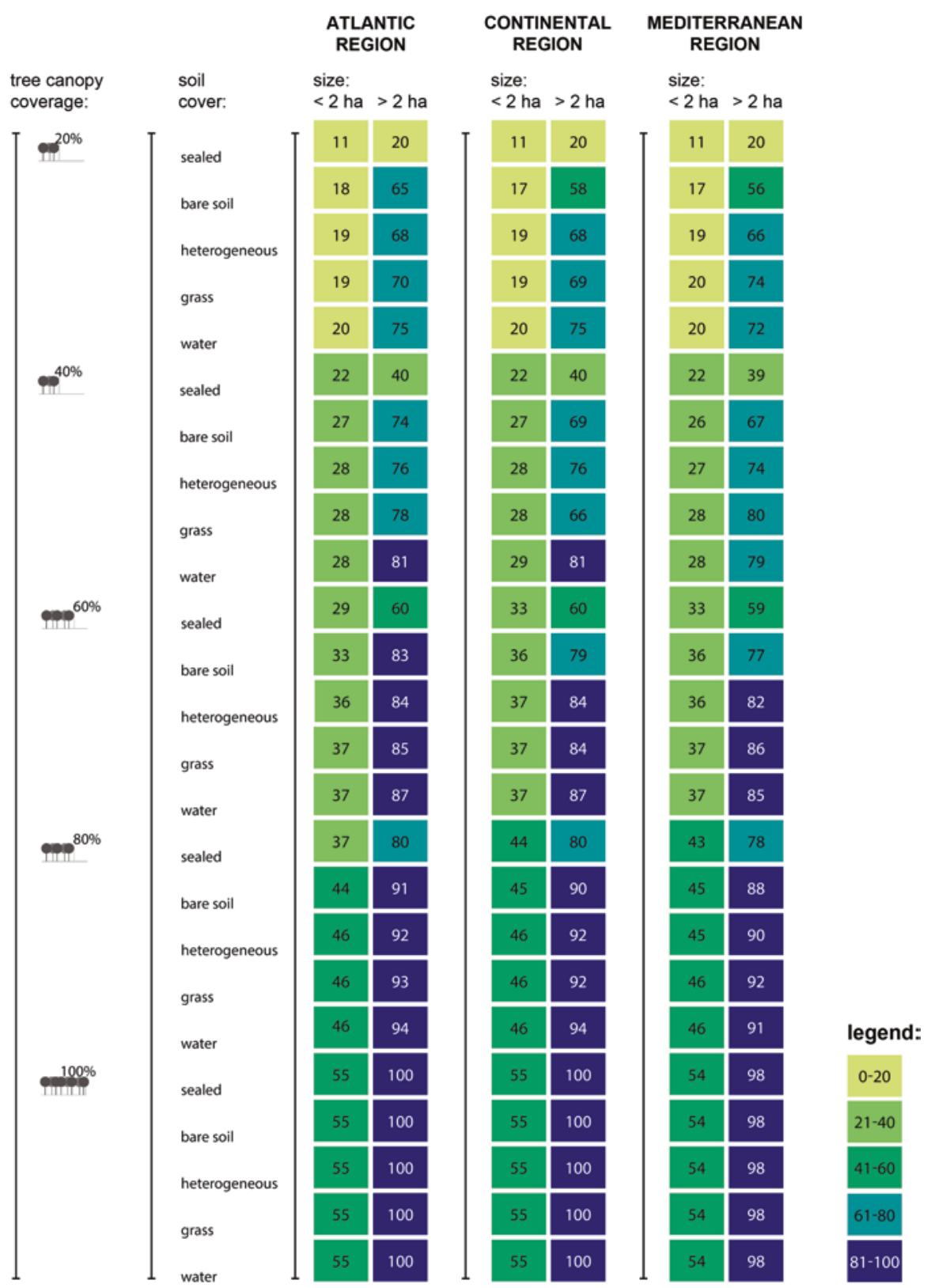

Fig. 4.2 Cooling capacity estimated for 50 UGI typologies in the climatic regions 


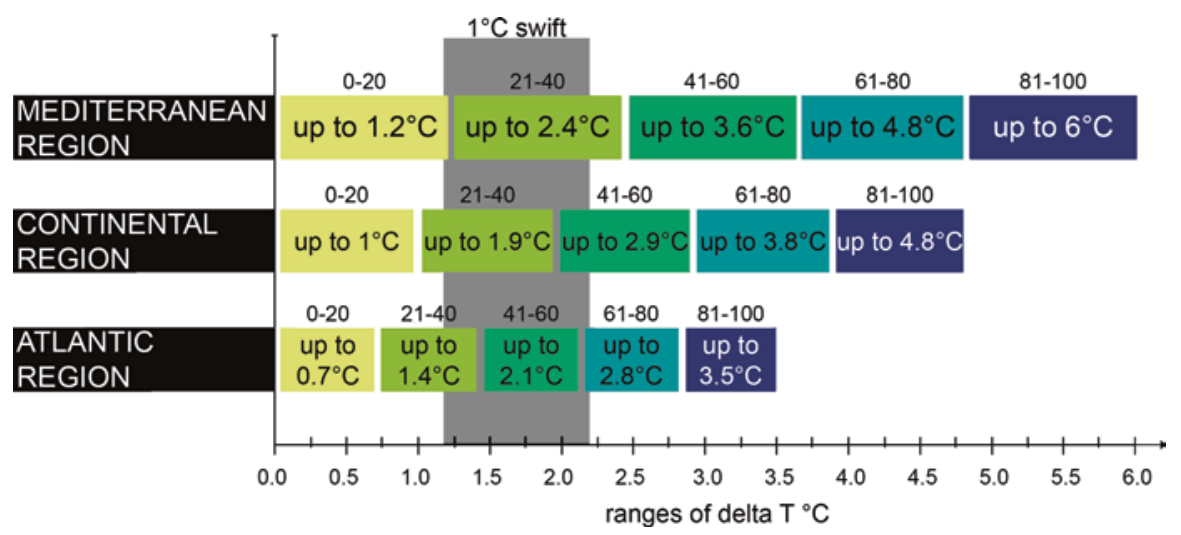

Fig. 4.3 Temperature variation (in Celsius degrees) for the same classes in the different climatic regions

\subsection{Application to the City of Amsterdam}

By way of example, the proposed approach was applied to the city of Amsterdam. A $10 \times 10-\mathrm{km}$ study area was selected to analyse the existing UGIs and to assess their cooling capacity. Amsterdam belongs to the cold temperate moist zone, corresponding to the Atlantic climatic region. Tree canopy coverage, soil cover and UGI size were mapped using available data (Fig. 4.4).

Overall, 74,653 patches, covering 8477 hectares, were mapped. The mapped UGI consist almost entirely (90\%) of water and of green areas with a tree canopy coverage below $20 \%$. A heterogeneous soil cover with tree canopy coverage below $20 \%$, sealed patches with tree canopy coverage below the $20 \%$, sealed patches with tree canopy coverage between 20 and $40 \%$, and grass soil cover with tree canopy coverage below $20 \%$ characterize the remaining $10 \%$ of the mapped UGI. Accordingly, Fig. 4.5 presents the results of the cooling capacity assessment with scores from 0 to 100 . Most UGI have a low cooling capacity: $34 \%$ of total UGI score less than $25,13 \%$ score between 25 and $30,22 \%$ score between 30 and 60 , and only the $1 \%$ of the UGI score more than 60 . As for the potential temperature reduction, it can be assumed that the $22 \%$ of UGI, which score between 60 and 30, can lower the temperature up to $2.1^{\circ} \mathrm{C}$.

From an urban planning perspective, the results can be used to identify possible actions to enhance the cooling capacity of least performing UGI. By way of example, Fig. 4.6 presents a set of possible interventions to upgrade an UGI with a cooling capacity score of 11 , characterized by size below two hectares, $20 \%$ of tree canopy coverage and sealed soil. The best results are provided by a combination of actions targeted at increasing the size and the tree canopy coverage, and improving soil cover. 


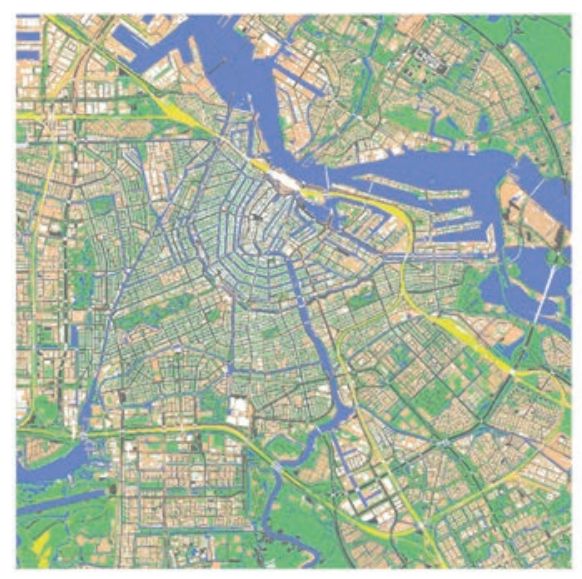

\section{Soil cover

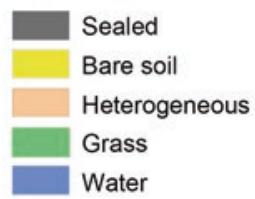

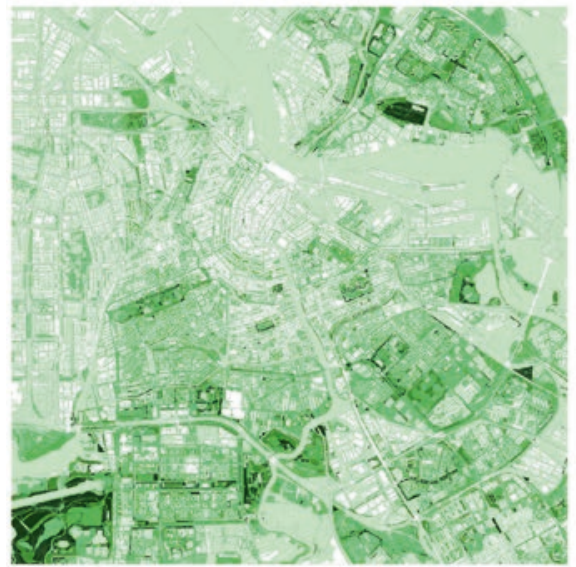

\section{Tree canopy coverage}

\begin{tabular}{|l|}
\hline $0-20 \%$ \\
\hline $20-40 \%$ \\
$40-60 \%$ \\
$60-80 \%$ \\
\hline $80-100 \%$ \\
\hline
\end{tabular}
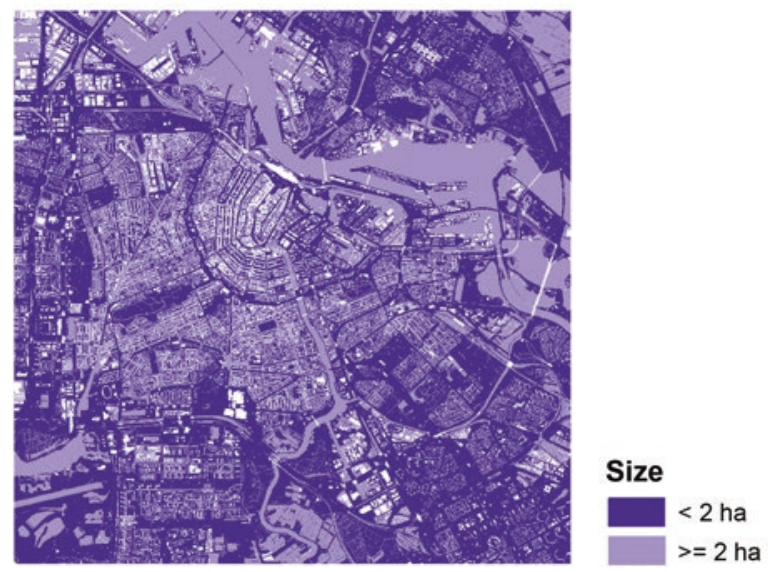

Fig. 4.4 Soil cover (top) tree canopy cover (middle) and size (bottom) of UGI in Amsterdam 


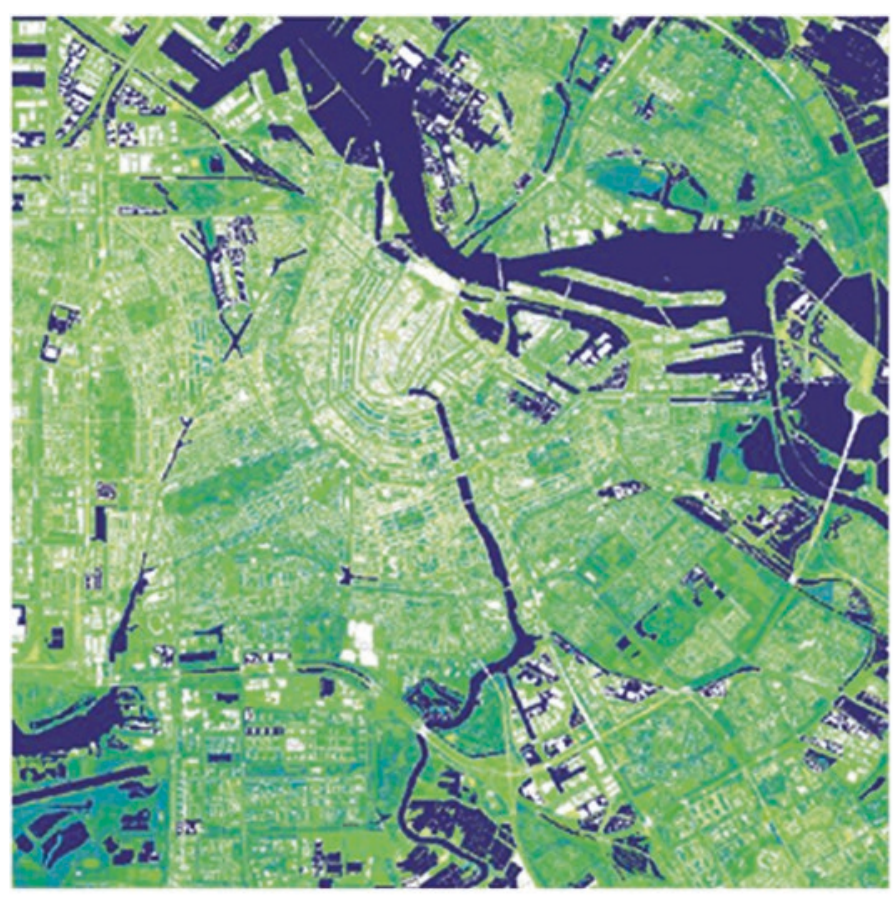

Cooling capacity

From 81 to 100

From 61 to 80

From 41 to 60

From 21 to 40

From 0 to 20

Fig. 4.5 Map showing the cooling capacity of UGI in Amsterdam

\subsection{Lessons Learned and Conclusions}

Scientific knowledge from different fields, such as ecology, planning, urban forestry and climate science, can improve UGI assessment, but an effort in terms of converting it into guidance that can improve urban planning processes is still needed (Norton et al. 2015). This chapter showed an example of how to draw on knowledge and data from different disciplines to improve the understanding of the relationship between the characteristics of UGI and the provision of ES. UGI represent a great potential for cities to adapt to multiple challenges; hence, the importance to take into account the design of UGI, and their capacity to supply a range of ES, in urban planning (Munang et al. 2013). However, the lack of suitable data and the complexity of modelling tools often pose a challenge to the improvement of UGI design in planning exercises. In this chapter, out of the bundle of ES provided by UGI, we focused on micro-climate regulation. The proposed approach links the relevant ecosystem functions and components of a UGI to its capacity to reduce heat, distinguishing among different typologies of UGI. The approach is designed to fit the urban scale and to work with input data that are sufficient to differentiate among the cooling capacity provided by different types of UGI, but still easily available during urban planning processes. 


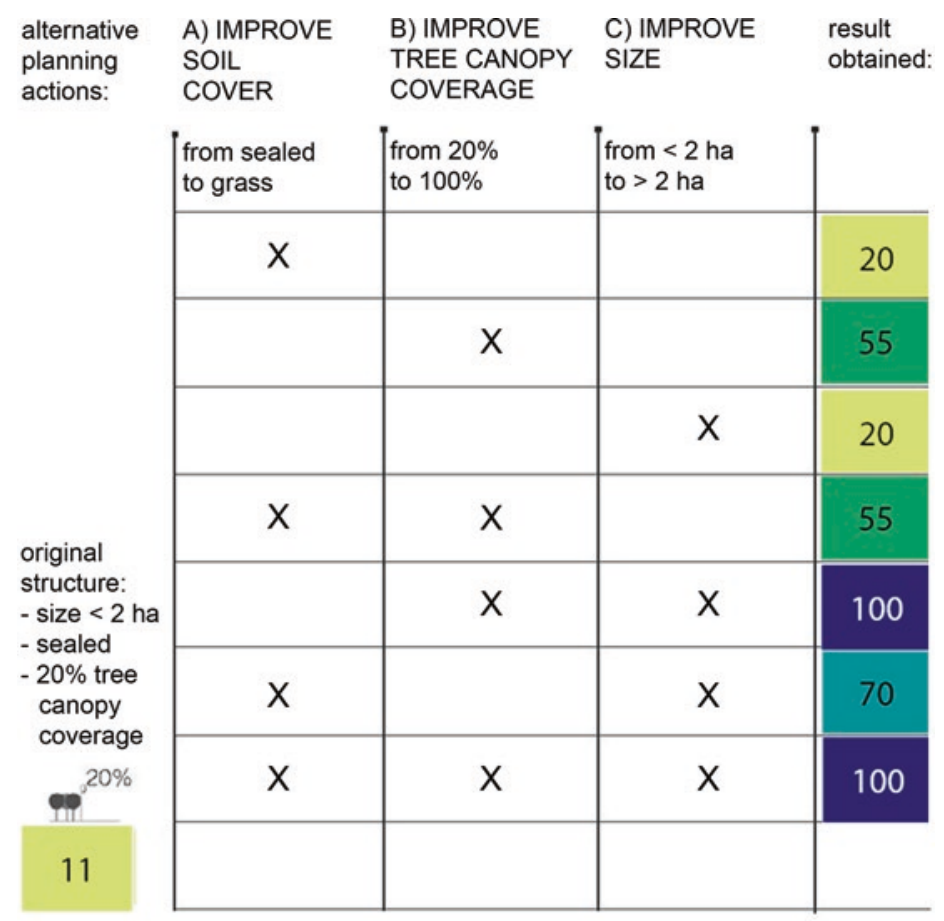

Fig. 4.6 Alternative actions (described in columns A, B and C) to upgrade an hypothetical UGI with a cooling capacity scores below 20 (characterized by a size smaller than two hectares, sealed soil cover and tree canopy coverage of $20 \%$ ), and the expected improvement in terms of cooling capacity score (last column)

As described in the chapter, the three most relevant components of UGI (i.e. tree canopy coverage, soil cover, and size) do not equally determine the cooling capacity. Generally, the most important component is size, followed by tree canopy coverage and lastly soil cover. Similarly, the climatic region of the study area is very important in determining the decrease in air temperature $\left({ }^{\circ} \mathrm{C}\right)$ provided by UGI. In particular, it was noted how a given UGI, with a specific class of cooling capacity, implies a different air temperature reduction depending on the climatic region. In the Mediterranean region, the same UGI can lower the temperature more effectively than in Atlantic or Continental regions, with the consequent different investment implications from a practical point of view.

The application to the city of Amsterdam demonstrated that the proposed approach requires only a limited set of input data, generally easy to obtain, to provide an overall cooling capacity assessment of the UGI. Several practical insights emerge from the case study application that are related to the different effects of the components in different conditions. For example, shading is more important in small areas than in large areas, making the increase of tree canopy coverage particularly interesting for small green spaces, especially compared to soil cover 
interventions. The latter are more adequate for large areas, while for small areas an enhancement of the cooling capacity can be obtained by increasing the tree canopy cover. An exception is the Mediterranean region where trees are more preferable than soil cover interventions. On the contrary, for large areas soil cover changes can provide much more interesting results in all three climatic regions, especially in the Mediterranean. However, a good balance in terms of tree-canopy coverage, soil cover type and size, as mentioned in the previous paragraph, is the strategy providing the best cooling capacity.

The approach, as it stands now, has three main limitations. Firstly, the computation of shading, evapotranspiration and the overall cooling capacity is based on a review of the available literature and on expert opinion. Further empirical evidence would make the approach stronger. Secondly, variables such as wind flow, city morphology, and tree species were not considered due to the choice for simplicity and synthesis, looking for a fair trade-off between accuracy of the assessment and a complexity in computations and data. Despite restricted to the most influencing factors, the analysis is flexible enough to provide solutions that are site-specific. For example, concerning tree species, the literature provides evidence about the fact that different tree species differently contribute to cooling due to different evapotranspiration functioning. Last, the proposed approach only considers the cooling capacity within the UGI, without addressing the effects outside its boundaries. Clearly, knowing the spatial extent of the cooling capacity beyond UGI boundaries would be interesting for urban planning, and for an analysis of the expected beneficiaries of different interventions. This challenge is addressed in the next chapter, where the analysis of the cooling capacity of UGI, as well as of other ES, is linked to an explicit assessment of different groups of beneficiaries, and the outcomes are used to inform urban planning.

Acknowledgments Marta Pérez-Soba and Michiel Van Eupen are acknowledged for contributing to this chapter.

Open Access This chapter is distributed under the terms of the Creative Commons Attribution 4.0 International License (http://creativecommons.org/ licenses/by/4.0/), which permits use, duplication, adaptation, distribution and reproduction in any medium or format, as long as you give appropriate credit to the original author(s) and the source, a link is provided to the Creative Commons license and any changes made are indicated.

The images or other third party material in this chapter are included in the work's Creative Commons license, unless indicated otherwise in the credit line; if such material is not included in the work's Creative Commons license and the respective action is not permitted by statutory regulation, users will need to obtain permission from the license holder to duplicate, adapt or reproduce the material. 